\title{
Toxicological Trends of Poisoning in a Tertiary Care Center of Western Uttar Pradesh
}

\author{
Pradeep Kumar Agarwal ${ }^{1}$, PranavKumar ${ }^{2}$, Harnam Singh ${ }^{3}$ \\ ${ }^{1}$ Associate Professor, ${ }^{2}$ Assistant Professor, ${ }^{3}$ Professor and Head, Muzaffarnagar Medical College, \\ Muzaffarnagar, U.P.
}

\begin{abstract}
Poisoning is a significant global public health problem which leads to nearly a million deaths per year. Incidence of poisoning is high in India. This study was carried out on poisoning cases reported to casualty department of Muzaffarnagar Medical College, Muzaffaranagar from $1^{\text {st }}$ January 2016 to $31^{\text {st }}$ December 2016. The main objectives of the study were to analyze pattern and demographic variables of poisoning cases. Data were collected and analyzed. A total of 72 cases (male: 46, female: 26) were included in the study. Maximum cases were of age group 21-30 years (30.5\%). More cases from rural area (75\%) were reported. Summer months saw maximum number of cases (37.5\%). Poisoning by Organophosphorus was seen in maximum cases $(31.9 \%)$ followed by Aluminium phosphide $(29.1 \%)$ and in maximum cases reason for poisoning was Intentional $(52.7 \%)$ and route of exposure was by oral ingestion $(84.7 \%)$. The study concludes that the burden of poisoning demands strategies for identification, prevention and its rational management.
\end{abstract}

Key Words: Poisoning, Organophosphorus, Aluminium phosphide, Casualty

\section{Introduction}

Poisoning is a major problem all overthe world, though the type of poison and the associated morbidity and mortality varies from place to place and changes over a period of time. Worldwide, an estimated three million cases of pesticide poisoning occurs every year, resulting in an excess of 250000 deaths. Of these $90 \%$ of fatal poisonings occurs in developing countries particularly amongst agriculture workers. ${ }^{1}$ An estimated total of 877000 people committed suicide worldwide in 2002 and around $28 \%$ of these cases are from South East Asia Region. ${ }^{2}$ The exact incidence of this problem in India remains uncertain but, it is reported that 1 to 1.5 million cases of poisoning occurs every year, of which nearly 50,000 dies. $^{3}$ The last quarter of century has seen tremendous advances in the fields of agriculture,

\section{Corresponding Author:}

Dr. PranavKumar,

Assistant Professor, Department of Forensic

Medicine,Muzaffarnagar Medical College,

Muzaffarnagar -251203, U.P, India

E-mail:docpranav3@gmail.com, Mob: 9027412219 industrial technology and medical pharmacology. These advances have been paralleled with remarkable changes in trends of acute poisoning in developing countries, including India. ${ }^{4}$ The commonest cause of poisoning in India is pesticide due to easy availability, agriculture based economy and poverty. In developing countries like India occupational poisoning is common due to illiteracy, unsafe practices like storing the pesticides at home and handling them without safety gear. ${ }^{5}$ Intentional and unintentional pesticide poisoning has been acknowledged as a serious health problem in many agriculture communities of low and middle income countries. WHO and other humanitarian organizations are coercing the authorities of different countries to ban the highly toxic pesticide and imposing restrictions to their access. Controlling accessto pesticide is not only critical in reducing self-directed violence, it is a key to preventing unintentional poisoning. Studies indicate, the ban must be accompanied by evaluation of agriculture needs and replacement with low risk alternative for pest control. ${ }^{6}$ The paucity of information on risk population, circumstances and toxics is a hurdle to effective poisoning prevention and targeted intervention programs. So the study is sought to characterize poisoning with regard to 
demographic factors and common toxic agents in our region.

\section{Material \& Method}

The present study was conducted in Muzaffarnagar Medical College, Muzaffarnagar, a tertiary care teaching hospital from $1^{\text {st }}$ January 2016 to $31^{\text {st }}$ December 2016. During this period a total of 72 cases of poisoning were reported to casualty department. This study was a prospective study. The relevant data was collected from casualty medical officer, treating doctors and from case file. Data related to name, age, sex, religion, marital status, economic status, type of poison ingested, mode of ingestion, rural $\&$ urban distribution of cases, occupation was collected in standardized proforma \& analyzed. Brought dead cases were not included in this study.

\section{Observations \& Results}

During our study period seventy two cases were admitted to the hospital with diagnosis of acute poisoning. Males were more prone to poisoning $(63.9 \%)$ as compared to females (36.1\%). (Table 1 ) The incidence of poisoning according to age revealed that there was an increasing trend of poisoning with increase in the age up to 30 years with a peak incidence in the age group 21-30 years which represented 22 (30.5\%) cases in this study and then declined. (Table 2) Among the 72 cases admitted to the hospital with diagnosis of acute poisoning 46 $(63.9 \%)$ cases were married followed by unmarried 25 (34.7\%). Incidences are more with rural areas 54 (75\%) then urban areas 17 (23.6\%). Out of 72 cases incidences was more in middle class $47(65.3 \%)$ followed by lower cases $24(33.3 \%)$. In present study incidence of poisoning was more in farmers $26(36.1 \%)$ and laborers 15 (20.8\%) (Table 3) Intentional poisoning was more common 38 (52.7\%) followed by accidental 30 (41.7\%). (Table 4) Out of all cases reported, oral ingestion was the most common route of exposure $61(84.7 \%)$ followed by inhalation 10 (13.9\%). (Table 5) Poisoning was more during summer season 27 (37.5\%) followed by winter 24 (33.3\%) and monsoon 21 (29.2\%). The poisons used were organophosphorus (31.9\%), Aluminium phosphide (29.1\%), Alcohol (13.9\%), rat poison (6.9\%), Kerosin (2.8\%). Among these Organophosphorus poisons are the most commonly abused poison followed by Aluminiumphosphide. (Table 6)

Toxicological Trends of Poisoning in a Tertiary Care Center of Western Uttar Pradesh

Table 1: Sex wise Distribution of Cases $(\mathrm{N}=72)$

\begin{tabular}{|l|l|l|}
\hline Sex & No. of Cases & Percentage (\%) \\
\hline Male & 46 & 63.9 \\
\hline Female & 26 & 36.1 \\
\hline Total & 72 & 100 \\
\hline
\end{tabular}

Table 2: Age wise Distribution of Cases $(\mathrm{N}=72)$

\begin{tabular}{|l|l|l|}
\hline Age (Years) & No. of cases & Percentage (\%) \\
\hline $0-10$ & 2 & 2.7 \\
\hline $11-20$ & 19 & 26.4 \\
\hline $21-30$ & 22 & 30.5 \\
\hline $31-40$ & 12 & 16.6 \\
\hline $41-50$ & 7 & 9.8 \\
\hline $51-60$ & 3 & 4.2 \\
\hline$>60$ & 6 & 8.4 \\
\hline Unknown & 1 & 1.4 \\
\hline Total & 72 & 100 \\
\hline
\end{tabular}


Table 3: Distribution of Cases According to Occupation ( $N=72)$

\begin{tabular}{|l|l|l|}
\hline Occupation & No. of Cases & Percentage (\%) \\
\hline Farmers & 26 & 36.1 \\
\hline Laborers & 15 & 20.8 \\
\hline House Wife & 10 & 13.9 \\
\hline Students & 9 & 12.5 \\
\hline Unemployed & 6 & 8.3 \\
\hline Service & 5 & 7.0 \\
\hline Unknown & 1 & 1.4 \\
\hline Total & 72 & 100 \\
\hline
\end{tabular}

Table 4: Distribution of Cases According to Reason for Poisoning ( $=72)$

\begin{tabular}{|l|l|l|l|l|l|}
\hline Reason & & No. of Cases & & Percentage (\%) & \\
\hline Intentional & 38 & & 52.7 & \\
\hline Accidental & & 30 & & 41.7 & \\
\hline Unknown & & 4 & 5.6 & 100 & \\
\hline Total & 72 & & 100 & \\
\hline
\end{tabular}

Table 5: Distribution of Cases According to Route for Poisoning ( $=72)$

\begin{tabular}{|l|l|l|}
\hline Route & No. of Cases & Percentage (\%) \\
\hline Oral Ingestion & 61 & 84.7 \\
\hline Inhalational & 10 & 13.9 \\
\hline Bite/Sting & 1 & 1.4 \\
\hline Total & 72 & 100 \\
\hline
\end{tabular}

Table 6: Distribution of Cases According to Type of Poisoning ( $N=72)$

\begin{tabular}{|l|l|l|}
\hline Poison & No. of Cases & Percentage (\%) \\
\hline Organo Phosphorus & 23 & 31.9 \\
\hline Aluminum Phosphide & 21 & 29.1 \\
\hline Alcohol & 10 & 13.9 \\
\hline Rat Poison & 5 & 6.9 \\
\hline Mosquito Repellant & 4 & 5.6 \\
\hline Benzodiazepine & 3 & 4.2 \\
\hline Kerosene & 2 & 2.8 \\
\hline Cannabis & 1 & 1.4 \\
\hline Corrosives & 1 & 1.4 \\
\hline Insect bite & 1 & 1.4 \\
\hline Unknown & 1 & 1.4 \\
\hline Total & 72 & 100 \\
\hline
\end{tabular}




\section{Discussion}

Poisoning cases, pesticide poisoning in particular impose a huge burden on the economy in developing countries. According to a study from India it is found that around $27 \%$ of pesticide poisoning cases require ventilation for varying periods which causes an unusual burden on already stretched health care system like India.7 It is known that the pesticides that cause most deaths in rural Asia and in the world, are WHO class I and II organophosphorus pesticides, causing an estimated 2,00,000 deaths.8-10 The present study shows that most of the cases belong to the age between 21 to 30 years which constitute $30.5 \%$ of the total cases. Thisobservation is consistent with the other studies6,11 In this study it has been observed that there is decreasing trend of poisoning cases after the peak of 21-30 years and it is least in extremes of life. Further it has been observed that most of the cases are due to organophosphorous and other insecticide poisoning. This is in accordance with the other studies. $(5,6,8-10)$ Out of total 72 cases studied $46(63.9 \%)$ were male \& $26(36.1 \%)$ were female which is consistent with other studies.11 In the present study $46(63.9 \%)$ cases were married \& around $25(34.7 \%)$ were unmarried. This is consistent with other studies 11 Rapid increase of indebtedness by farmers and failure to reimburse due to natural calamities like draught is the reason behind the increase in poisoning during summer season.11,12 India being an agriculture nation, handling of pesticides is a routine practice by farmers and their family members. House hold and agricultural agents were associated with most poisoning due to easy availability of these agents \&inadequate knowledge to support their safe residential use. Studies have shown pesticides is the most common toxic agent involved in poisoning.11-14 In the present study intentional poisoning is more common which is consistent with other studies. (Mentioned above)In the present study it has been observed that incidences are more among rural population(75\%) than urban population $(23.6 \%)$ which is consistent with other studies.11-14 It is worth noting that incidences of poisoning is more in middle class 47 (65.3\%) followed by lower class 24 (33.35) which is consistent with other studies.11 In the present study it has been observed that oral ingestion is the most common route of exposure $61(84.7 \%)$ followed by inhalation 10 (13.9\%). 12-14

\section{Conclusion}

Increased Intentional Poisoning in adults emphasizes on importance of Counseling \& awareness about depression and stress affecting the major strata of the Society which increases suicidal tendencies.As in India, two third of populations economy is based on agriculture, of which majority lives in rural area. The reason of intentional poisoning by farmers is indebtedness, which may be due to natural calamities like- draught, Flood, etc.Authentic data on poisoning was not available not only from India but from entire SEAR (South East Asia Region). WHO States that many cases go unnoticed and mortality may actually be higher. Involvement in poisoning young male group which is most active and productive, puts huge burden on economy and social loss to the country.Pesticides again are clear culprit in most of the cases. In one sentence it may be stated that self harm pesticide poisoning is most common type of poisoning which is more common in rural areas and most of the cases are from age group 21-30 years.

\section{Conflict of Interest: Nil}

Source of Funding: Self-funded.

Ethical Permission: Institutional ethical committee.

\section{References}

1. WHO Library Cataloguing - in - publication Data: Guns, Knives, and pesticides: reducing access to lethal means. ISBN 978924 1597739. 2009

2. WHO Library Cataloguing- in - publication Data: Safar access to pesticides: reducing access to Community interventions. ISBN 9241594896. 2006

3. Aggarwal P, Handa R, Wali J.P. Common poisoning in India. Proceedings of National workshop on practical and Emergency Toxicology; 1998; (1): 25-31.

4. Singh D, Jit I. 'Changing Trends of acute Poisoning in Chandigarh Zone'. Am J Forensic Med. Patho. 1999; 20 (2):203-210.

5. Reddy KSN. The essentials of Forensic Medicine and Toxicology. 33rd ED;2014,P.500

6. Singh $\mathrm{J}$ Etal. Trends of Poisoning in a Tertiary Care Centre of North West Uttar Pradesh. JIAFM. 2015;37 (4): 396-399

7. Rao CHS, Venkateswarlu V, Pesticide Poisoning in South India - Opportunities for Prevention and Improved Medical Management Trop Med Int. Health 2005; 10 (6): 581-588 
8. Buckley NA, Etal. Where is the evidence for the management of pesticide poisoning - is Toxicology fiddling while the developing world burns? Journal of Toxicology Clinical Toxicology. 20014: 113116.

9. Eddleston M. Patterns and problems of deliberate self-poisoning in the developing World. Quarterly Journal of medicine. 2000; 93: 715-731.

10. Gunnell D, etal. The global distribution of fatal pesticide self-poisoning: systematic review. BMC Public health. 2007b; 7: 357.
11. Dhattarwal S.K. etal. Profile of Deaths due to Poisoning in Rohtak, Haryana; JFMT 2001;18(2): (28-29)

12. A Sawari Raut etal. Toxicology pattern of Poisoning in urban hospital of western India. J Young Pharm. 2017; 9(3): 315-320.

13. Kumar SV. etal. A study on poisoning cases in a Tertiary care Hospital. JNSB \&M 2010;1: (35-39)

14. Banerjee I etal. Pesticide use pattern among farmers in a rural District of west Bengal, India.JNSB\&M 2014;(15): (313-316). 